\title{
Tramas de las resistencias socio territoriales en Guatemala
}

Mariana López de la Vega

RESUMEN: En este artículo, se presenta de manera general la conflictividad social en Guatemala centrada en el despojo territorial para mostrar algunas de las tramas de la organización y de las resistencias de las comunidades, pueblos indígenas y colectividades de mujeres, así como la relación que se da entre las comunidades y Estado. Las reflexiones en el trabajo versan sobre las dificultades, retos y apuestas políticas que presentan las $y$ los defensores socioterritoriales en Guatemala.

PALABRAS CLAVE: Territorio. Despojo. Resistencia. Estado. Comunidades.

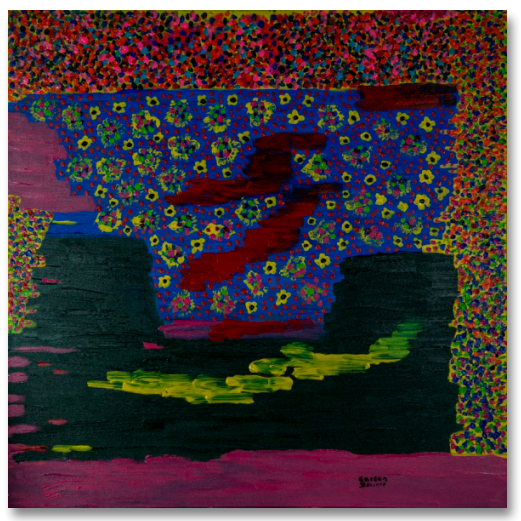

\section{Frames of socioterritorial resistances in Guatemala}

\section{Mariana López de la Vega}

Posdoctoranta en el Centro de Investigaciones sobre América Latina y el Caribe en la UNAM. Doctora en Estudios Latinoamericanos y profesora de Historia de la Educación en América Latina en UNAM. E-mail: mar.lopezdelavega@gmail.com
ABSTRACT: In this article we will present in a general way the social conflict in Guatemala focused on the territorial dispossession to show some of the plots of the organization and the resistances of the communities, indigenous peoples and collectives of women, as well as the relationship that occurs in the relationship Communities-State. We will reflect on the difficulties, challenges and political bets of the communities that defend the territory.

KEYWORDS: Territory. Dispossession. Resistance. State. Communities.

RECEBIDO EM: 21/04/2019

APRoVADO EM: 27/07/2019 


\section{Introducción 1}

La profundización de las políticas neoliberales en Guatemala tiene como punto de inflexión el último Conflicto Social y Armado Interno $(\mathrm{CAI})^{2}$ en la historia del país $\mathrm{y}$, dentro de las políticas que se han llevado a cabo para asegurar la reproducción del capital, el despojo territorial que ha llevado a una gran conflictividad social. Para abrevar el ánimo sobre ello, consideramos importante marcar que el proceso de paz en Guatemala, tras un conflicto de más de 36 años, puso de manifiesto la entrada de un nuevo ciclo sociopolítico, ya que los acuerdos para la firma de la paz fueron expresión de una coyuntura política en la cual la presión internacional por el fin del conflicto era fuerte y se buscaban inversiones de capital extranjero para sustentar el Estado.

Las fuerzas armadas contaban con una presencia directa en el gobierno y en su administración, lo que afectaba en la conducción del Estado y la capacidad de aglutinar consensualmente a sectores de la clase dominante. La milicia también estaba debilitada tras décadas de uso continuo de poder contrainsurgente. Así, el modelo necesitaba una modificación, dada la crisis económica, los problemas internos de la élite en el poder y el aislamiento internacional por las masacres cometidas. Ello conllevó una estrategia para desplazar la presencia militar en el gobierno, de la cual formó parte el golpe de Estado realizado en 1982, ya que:

1 Este artículo es resultado del Programa de Becas Posdoctorales en la UNAM realizada en el Centro de Investigaciones sobre América Latina y el Caribe, asesorada por la doctora Silvia Soriano Hernández.

2 En el siglo pasado, se dio el último conflicto social y armado interno en el país - lo datamos aproximadamente de 1960 a 1996 - donde se disputaban diferentes proyectos de construcción de nación, principalmente, entre la clase política en el poder y las diferentes insurgencias agrupadas en la Unidad Revolucionaria Nacional Guatemalteca (URNG), que concebían de forma distinta el papel y la función del Estado. En estas décadas, las violaciones a los derechos humanos y el terrorismo de Estado eran una constante. Existe una fuerte discusión en las formas de nombrar este periodo ya sea conflicto, guerra o enfrentamiento, de acuerdo con los actores políticos y sectores que la nombran. Muchas comunidades, por ejemplo, lo nombran en el ámbito coloquial como guerra. Para este artículo, nombraremos "conflicto social y armado", atendiendo la situación sociopolítica que tiene este proceso, así como los actores - tanto el Estado como las organizaciones insurgentes que estuvieron en él. 
en primer lugar, dio inicio a la retirada militar del control del gobierno de manera ordenada y exitosa. Permitió al ejército continuar en el control del poder sin los riesgos de la administración del gobierno...Puso término a la modalidad de casi dos décadas, de regímenes políticos electorales encabezados por militares y creó las condiciones institucionales para iniciar la democratización del sistema político (TORRES RIVAS; AGUILERA PERALTA, 1998, p. 79).

Los gobiernos militares post golpe de Estado desplegaron el poder contrainsurgente, continuando el terrorismo estatal, llevándolo hasta el genocidio. ${ }^{3}$ Ese terrorismo fue parte de la estrategia de la clase en el poder para "ganar" la guerra y dar paso - de forma contradictoria - a la transición a gobiernos civiles. Así, un gobierno civil permitiría que Guatemala pudiera acceder a ayuda externa, se mantuviera el control militar sin llevar sobre si la administración gubernamental. Finalmente, los acuerdos se firmaron en diciembre de 1996 entre el gobierno y la Unidad Revolucionaria Nacional Guatemalteca (URNG) ${ }^{4}$ y se dio una reforma adaptativa del Estado que implicó un reacomodo "democrático" neoliberal.

En este artículo, presentaremos de manera general la conflictividad social en Guatemala centrada en el despojo territorial, para mostrar algunas de las tramas de la organización y de las resistencias de las comunidades, pueblos indígenas y colectividades de mujeres, así como las dificultades, retos y propuestas que estos tienen. Para ello, contamos con cuatro apartados: el primero versa sobre el Estado, la reconfiguración de capital y el despojo territorial en Guatemala. Después damos cuenta de parte de la organización

3 Como política de Estado, ésta se puede ejemplificar mediante el Plan Victoria 82, el Plan Firmeza 83 y el Plan de Operaciones Sofía, los cuáles muestran la estrategia del ejército y su responsabilidad estatal. Si se desea ver el documento completo, buscar por Comisiones... (2011).

4 Los Acuerdos de Paz conllevaban modificar la conformación estatal y la organización de sus estructuras políticas. El Estado contaba con instituciones precarias y con poderes disminuidos, compensándolos con dominación y cooptación. Para los pueblos indígenas, uno de los retos era su reconocimiento político, jurídico y cultural; lo que implicaba el uso, respeto y disfrute de su sujetidad política ante una sociedad con profundas estructuras racistas que han cimentado la historia nacional. 
social y comunitaria, por medio de diálogos, entrevistas y búsquedas de archivo donde ejemplificaremos tramas de las resistencias comunitarias. En un tercer apartado, daremos cuenta de algunos de los tejidos y trabajos realizados por mujeres y concluimos con un conjunto de reflexiones donde problematizaremos los retos y aportes de las luchas y resistencias en el tiempo presente.

\section{Estado, reconfiguración de capital y despojo territorial}

El Estado de Guatemala se enfrenta hoy a una relación de capital mundial, en la cual cada vez depende más de la economía internacional. Por eso, los intereses de las compañías transnacionales han impuesto y acordado con el Estado reglas para operar -como es el caso de los cafetales y las hidroeléctricas, por mencionar algunas - en el territorio guatemalteco, donde los bienes naturales están en disputa.

Esto lo han vivido las comunidades, especialmente las indígenas, como una afrenta profunda ante la entrada avasalladora de megaproyectos que arrebatan sus territorios impulsados por el bloque de poder, constituido por una parte de la oligarquía, la clase política, los militares y los grupos transnacionales. Para lograr esto, el Estado ha podido consolidarse y ha tratado de legitimarse con una precaria hegemonía por la vía del miedo, de la coerción y del uso de los medios de comunicación para generar consensualidades en la población. Guatemala se ha transformado en su configuración estatal, del contrainsurgente en la época del CAI a uno que busca el control de la sociedad civil por medio de la "seguridad", legitimando las relaciones consolidadas por los militares y la clase política en el poder, así como la apropiación de exigencias de la sociedad civil como el alto a la corrupción en la cual la clase política ha sabido capitalizarla para mantener fuerza. ${ }^{5}$

5 Un ejemplo de ello fue la llegada al poder del presidente Jimmy Morales, ex cómico de televisión que trabajó como eje de su campaña un gobierno honesto ante la crítica de su antecesor, Otto Pérez Molina, quién fue juzgado por corrupción. Sin embargo, este mandatario expulsó a Iván Velásquez, que preside la Comisión Internacional contra la Impunidad en Guatemala, en cuanto se empezó a investigar el financiamiento de su campaña para llegar a la presidencia 
Por ello, uno de los retos de la sociedad y de las comunidades es transformar las relaciones sociales al tiempo de construir tramas que refuercen los ámbitos colectivos y comunitarios.

El Estado guatemalteco, en este sentido, ha priorizado sus prácticas políticas en pro de los intereses globales, sobre todo trasnacionales, viabilizando el proceso económico estructural global, aún no fuera consensual (BASTOS, 2015). Esto lo podemos ejemplificar con la firma del Tratado de Libre Comercio con Estados Unidos en el 2005, el cual tuvo como repercusión la entrada de más capital transnacional en el país. Lo mismo sucedió en la política energética con el impulso de la Franja Transversal Norte (SOLANO, 2007), la cual conlleva una recolonización. Así como la anuencia y priorización de la "integración regional" como lo buscado por el Proyecto de Integración y Desarrollo de Mesoamérica, esas iniciativas buscan ampliar la obtención de materias primas, mano de obra explotada y despojo territorial. Otra cara de la intervención se ha dado con la consolidación de "proyectos sustentables" - si bien algunas iniciativas permitieron, reagruparon y posibilitaron la organización comunitaria autónoma, otras dieron la entrada a organizaciones no gubernamentales que, acompañadas con otros intereses, impusieron agendas de trabajo que, en ocasiones, desviaban las prioridades y despolitizaban o rompían organizaciones comunitarias, ya por la necesidad de financiamiento o por políticas paternalistas (LÓPEZ DE LA VEGA,2013).

En los últimos años, han aparecido varias industrias y proyectos neo extractivistas como son las licencias que se otorgaron el año 2016, para realizar proyectos de minería metálica, hidroeléctricas, petróleo (BRAN-GUZMÁN, 2017). ${ }^{6}$ Estos proyectos reproducen esquemas neocoloniales de extracción con la anuencia del Estado-nación, ya que se otorgaron permisos, concesiones de

6 Es importante hacer notar que en "Guatemala para el 2016, El Ministerio de Energía y Minas registraba 81 licencias vigentes para minería metálica frente a 323 solicitudes en trámite para el mismo sector" (BRAN-GUZMÁN, 2017, p. 44). Entre éstos, están 11 proyectos para la minería, 15 hidroeléctricas, 3 plantaciones y uso de químicos, 1 de petróleo, 1 área protegida, 1 proyecto turístico, 1 extracción ilegal de minerales y uno que trata sobre el servicio de energía eléctrica. 
licencias de exploración y explotación sin conocimiento, consulta e información para la población que será afectada. Al mismo tiempo, para otros sectores de la sociedad civil, se plantea un discurso sobre la necesidad de "progreso" sin problematizar sus consecuencias y, ante las movilizaciones de las poblaciones, de luchas y resistencias, paulatinamente se ha modificado el Código Penal para criminalizar las movilizaciones.

Las y los actores que persisten en organizarse en defensa de sus derechos, de su territorio o bienes naturales son amedrentados y criminalizados en varias formas:

[...] Porque el efecto psicosocial de la represión es ése: prolongar en el ámbito nuevo de la paz política el terror que se prolonga en ella y que la circunda, pero ahora pacificados, como si no estuviera. La guerra aparecerá entonces como un accidente en la sustancia de la política, como si no formara parte de su esencia. Viniendo desde la represión y de la guerra, la paz de la política nos saca del insomnio, pero nos sumerge en el adormecimiento y en el sueño (ROZITCHNER, 2000, p.107).

En los últimos tiempos, ante el incremento de la conflictividad social, el Estado de Guatemala ha retomado el recurso de la violencia estatal, el estado de sitio, el hostigamiento, para no dejar duda de que puede ocupar las estrategias de terror en cualquier momento, principalmente en las comunidades. Esto es relevante, porque mantener lo comunitario implica un profundo trabajo interno tanto individual como colectivo, para afrontar las secuelas de la represión y la guerra para transformarlas en proyecto y organización. Para ello, necesitan espacios de dialogicidad y encuentro con la diversidad de actores de la sociedad. Sin embargo, la clase política y el bloque dominante han logrado que sus intereses se presenten como los de la mayoría, aprovechando que una parte de la sociedad civil ha asumido el trabajo de construcción de ciudadanía - tomando como referencia la lucha por los derechos sociales -, en una suerte de ilusión "democrática" que ante el recuerdo del golpismo ha tratado de encubrir la opresión, desigualdad y racismo existentes, planteando que el cambio de gobiernos civiles no 
están entretejidos con el terror y el miedo como una mediación esencial.

La gelatinosa hegemonía estatal "universalizó" un proyecto despótico capitalista que incorporó obligadamente a las grandes mayorías conformadas por los pueblos originarios. En la relación Estado-sociedad civil, podemos encontrar que el actual proyecto político dominante se ajustó a formas de gobernabilidad autoritaria, que mantuvieron las formas instaladas históricamente bajo los gobiernos militares. Hoy se ha vuelto una situación de crisis estatal, a poco más de 20 años de los Acuerdos de Paz (MORENO, 2015). Las instituciones políticas no dieron una respuesta satisfactoria a las demandas de la sociedad civil que emanaron, en buena medida, de la reflexión sobre el conflicto y algunas de ellas se articularon como demandas comunitarias en los Acuerdos de Paz. Sin embargo, en el proceso, se fortaleció el poder militar y se ocupó como mediación los recursos del miedo, del terror y del signo en tanto las violencias que se desarrollaron en gran parte contra la población maya y las secuelas psico sociales que están hasta nuestros días. Para llevar a cabo el paso de los megaproyetos, se siguen utilizando prácticas de guerra y los ámbitos coercitivos son una de las mediaciones privilegiadas, en tanto ocupa formas legales e ilegales, como por ejemplo con los grupos paramilitares al servicio de las grandes compañías. La coerción también refuerza los ámbitos de cooptación en tanto los sobornos, la corrupción, las redes de poder en pro de intereses específicos son claras. La política estatal tiene también como eje la promoción de la explotación de los bienes naturales en tanto es claro la aprobación de licencias de minería, de extracción de petróleo, por mencionar algunas que también responden a las dinámicas regionales y globales.

Ante este neoliberalismo militarizado (BASTOS; DE LEÓN, 2015), varias comunidades de Iximulew, en Guatemala, se están movilizando en la defensa de sus derechos y en la búsqueda de justicia, ya sea en la defensa de su territorio, en el fortalecimiento de su organización interna, en la defensa comunitaria y en el trabajo del cuerpo territorio como en proyectos diferenciados para la reproducción de la vida, que van desde la organización de consultas comunitarias, la reorganización de espacios vitales 
- como es el trabajo de sanación colectiva en el cual se recupera y/o se refuerza la sujetidad de la comunidad como un actor capaz de determinar las transformaciones de su territorio - hasta la incansable lucha por varias formas de justicia ante los largos memoriales de agravios. A continuación, daremos cuenta de algunas formas de resistencias encaminadas a mantener y defender el territorio engarzado con la fuerza de lo común (NAVARRO; PINEDA, 2011).

\section{Resistencias, organización social y comunitaria: múltiples tramas comunitarias}

varias comunidades de Iximulew, en Guatemala, se están movilizando en la defensa de su territorio. En todas estas experiencias, se busca recuperar la sujetidad política de la comunidad como un actor capaz de determinar las transformaciones de su territorio y decidir sobre su camino.

Cuando hablamos del territorio, lo podemos entender como "el espacio físico, social, cultural y espiritual en el que se organizaron [las comunidades] para producir y reproducirse, el marco geográfico social e histórico del que, con la práctica, el conocimiento y la experiencia se fueron apropiando" (MEMORIA HISTÓRICA, 2013, p. 378). El territorio también es el espacio de interracción entre las comunidades y la naturaleza, es simiente de la posibilidad de la reproducción de lo comunitario y de la vida histórico-social y cultural. En un mismo territorio, se conjugan diversas relaciones sociales que impactan de manera desdoblada en acciones políticas que se realizan no sólo en el ámbito local, sino en el regional e internacional, es decir, pasan por las necesidades de las comunidades, las que se plantean dentro del Estado y de las empresas. Esto se traduce en políticas que, en algunos momentos, sobreponen las relaciones mercantiles a las familiares y comunitarias (MANÇANO FERNANDES, 2009) y tienen influencia también en los ámbitos culturales y sociales.

Actualmente, las comunidades tienen como principal consigna colectiva la defensa del territorio y muchas de ellas realizan una crítica profunda a los fundamentos liberales del Estado-nación, 
en tanto los ordenamientos territoriales impuestos y la forma de concepción hegemónica de la naturaleza (que la contempla como inanimada y al servicio de los seres humanos). Así la defensa del territorio, para muchas comunidades, se remonta en una historia de larga duración, en la cual se retoman las formas ancestrales. Como bien plantea Amaité, ${ }^{7}$ del territorio-pueblo Ixil:

Tenemos nuestras aguas, las podemos utilizar, pero sin dañarlas, pero yo creo que ahora esa es una de las luchas la del territorio, el territorio implica pueblo, todo lo que tiene. Ahora nos quieren quitar el territorio, primero nos querían desaparecer y para quitarnos el territorio tendrían que eliminarnos, entonces tampoco vamos a permitir, es por eso por lo que la juventud tiene que ponerse pilas, porque si no, ¿quién va a seguir? ... No es que estemos incitando a la guerra, que seamos violentos. No sé si lo traemos en la sangre desde que se instalaron los primeros abuelos, pero es bonito saber cuándo ellos se instalan, que dicen nos vamos a instalar acá... y pensaron que las montañas es un cordón de protección y como los abuelos visualizaron su seguridad; contra el hombre, los vientos, los temblores... somos muy afortunados, es una dicha...

La defensa del territorio se realiza a partir de una crítica a la manera como está organizado el capital y ha sido una constante de los pueblos desde la invasión, lo que ha caracterizado sus resistencias. Por ejemplo, en el idioma Ixil, hay varias formas de nombrar la resistencia:

Entrevista Colectiva: (Resistencia...) Son dos palabras, xak bate o kuku bate, es igual a que estemos posesionados, o sea que estemos en nuestro lugar... La fuerza de cuando se habla de la resistencia es, por ejemplo: porque dicen así que no es que no más que se va a rendir, el ejército trata de capturar a la población

7 En el artículo, retomamos diálogos y entrevistas realizados a diferentes personas de la comunidad como parte de la investigación doctoral sobre el pueblo territorio Ixil, entre el 2011 y el 2014. Amaité es una mujer integrante de la comunidad pueblo Ixil, es guía espiritual y parte de la alcaldía indígena. Los nombres de las y los dialogantes se han modificado en la presentación del texto. Cuando está, la sigla DC hace referencia a un diálogo colectivo. 
y tampoco nos vamos a dejar por eso es por lo que estemos posesionados en nuestro lugar...porque la población siempre cambia su lugar, -pero está en su lugar, aunque se va a otro lugar...

Por ello, mantener el territorio, estar en el lugar de uno o una es uno de los puntos nodales de la resistencia. Para lograrlo, la comunidad ha desarrollado diferentes formas de organización que van desde movilizaciones populares hasta rencuentros comunitarios que buscan reforzar o recuperar los lazos de memoria e identidad para potencializar los movimientos de lucha. Dentro de los análisis de varias comunidades y pueblos, los periodos de despojos y resistencias plantean que se han dado en inflexiones específicas espacio-temporales, siendo una de ellas esta nueva reconfiguración de capital, la cual está centrándose en ampliarse en nuevos territorios. Por ejemplo, en algunos diálogos, integrantes de la comunidad-pueblo ixil presentan cortes de los ciclos históricos de acuerdo con diferentes momentos de dominación, planteando cada uno de ellos como el nacimiento de "diferentes huevos" que renacen de acuerdo con cada explotación o despojo histórico. La metáfora plantea una unidad histórica de dominación sobre el pueblo Ixil, es decir, al momento de la invasión se dejó un huevo que renació después en la Colonia y así sucesivamente hasta la actualidad. Uno de los ejes de esta dominación es el despojo del territorio que forma una continuidad desde la invasión-conquista hasta nuestros días, representada y ubicada en el pensamiento en espiral que plantea las complejidades del dominio, entendiendo por ello el despojo, desprecio, racismo y colonialidad. Eso implica abrir el análisis a partir de estos elementos. Por ejemplo, el vocero del Consejo de pueblos Mayas planteó:

[...] el primero comenzó con la llegada de los españoles y su saqueo de nuestra tierra, el segundo corresponde al despojo de tierras a nuestros pueblos y la imposición de trabajo forzados por las grandes plantaciones en el siglo XIX y XX. El tercer despojo se produjo por el daño del conflicto armado interno que vivimos por más de treinta años a finales del siglo XX (PANEZ PINTO, 2014, p. 01). 
Esta entrada del despojo territorial por los megaproyectos extractivistas se refiere a un nuevo ciclo, en el cual se concibe la larga duración de las resistencias en tanto defensa del territorio y el continuum de violencias.

Ante ello, las comunidades han generado diferentes estrategias y se han reagrupado en asambleas comunitarias. "Se habló de la Asamblea como la palabra de los pueblos, que proyecta el conocimiento y el entendimiento común de un pueblo, constituye la base para la resolución de sus problemas y la guía para la toma de decisiones colectivas" (MEMORIA HISTÓRICA, 2013, p. 378). Estas asambleas se han mantenido en todas las condiciones aún con las fuerzas disgregadoras de lo común, sobre todo en los momentos más conflictivos como la guerra, en la cual las Comunidades de Población en Resistencia (CPR) seguían realizando sus asambleas plenarias para organizar el trabajo y la seguridad. Ellas se fueron actualizando de acuerdo a las transformaciones históricas y políticas:

Pero el milagro de la Resistencia no hubiera sido posible sin el esfuerzo de la organización, que incluyó: La pluralidad de medios de lucha (autodefensa, lucha comunitaria, lucha política, lucha militar). Sólo la población no hubiera podido sobrevivir, pero solo la guerrilla sin la implicación de una mayoría de personas no hubiera sido capaz de impulsar la Resistencia; la cohesión (esfuerzo, solidaridad, disciplina, orden, unidad alrededor de objetivos comunes); la participación masiva, no contradictoria con la cohesión anterior, la convicción y la lucha por un proyecto: los factores de conciencia que apuntalaron la base material de la Resistencia (CABAÑAS, 2000, p. 100).

Otro mecanismo es la consolidación de consultas comunitarias ${ }^{8}$ (VILLATORIO GARCÍA, 2017) como medio de que se respeten los derechos de los pueblos y sus formas de habitarlo. Ellas también plantean la preservación del territorio, ya que se tiene claro que

8 Como las realizadas en Totonicapán, en 2015; en Chuarrancho, en el 2009; en Santiago La Laguna, en 2014, por mencionar algunas. Cf. Villatorio García (2017). 
los bienes naturales se requieren cuidar, pues de ellos depende la existencia de la misma comunidad. Las consultas comunitarias se han dado en varios departamentos de Guatemala y es un derecho fundamental de los pueblos indígenas, sobre todo si hay proyectos que se quieran implementar y que afectan sus territorios.

Una de las consultas populares más emblemáticas es la realizada en 2005 por las y los mayas- $k^{\prime} i c h e^{\prime}$, en Sipakapa, en contra de la mina Marlin, perteneciente a la empresa canadiense Goldcorp. Esto logró que otros pueblos y comunidades se alertaran avivando la creación de consejos en diferentes territorios. La realización de las consultas comunitarias tiene como objetivos la discusión y elaboración de propuestas, la difusión de acuerdos y la toma de responsabilidades sobre lo que se quiere realizar en cada territorio. Ellas retoman prácticas ancestrales para definir como se quiere mantenerlo, además de discusiones de cómo se concibe y entiende el desarrollo para las comunidades.

De las 85 consultas comunitarias registradas hasta el 2017 por la Unidad de Mediación de la Oficina del Procurador de Derechos Humanos, la mayor parte ha sido sobre minería, después sobre hidroeléctricas y posteriormente sobre otros proyectos. Se han realizado en varios departamentos como Huehuetenango, Quetzaltenango, Quiché. Sin embargo, para otras áreas y comunidades, las consultas no se han podido realizar y un poblador de la comunidad Ixil, en Nebaj, se pregunta:

Ka: Se oye que el área Ixil está muy organizada, muy apoyada por varias instituciones y organizaciones internacionales por que el área Ixil fue afectada por el Conflicto Armado Interno, pero, la pregunta es ¿dónde está la información?, ¿por qué el área Ixil quedó atrasada?, ¿por qué en ningún municipio se ha desarrollado la consulta? La pregunta, mi reflexión, ahora mi conocimiento, mi análisis, es que hay "mucha organización" en el municipio y que ésta es otra de las divisiones. Me di cuenta porque en el área Ixil (estamos) bien llenos de instituciones y ¿dónde está la consulta?... La información que nazca a las comunidades y entre más organizaciones, más proyectos con la cooperación internacional, más divisiones... 
Es relevante mencionar, por ejemplo, que, aunque en el área Ixil hay muchas instituciones y organizaciones no gubernamentales, no se ha logrado llevar a cabo las consultas comunitarias, pues se encuentra en proceso la consolidación orgánica de éstas. En el marco de este trabajo, también se han realizado foros que plantean que ante "Una misma situación, una misma Resistencia". Eso ha implicado fomentar la unidad y ubicar las problemáticas colectivas. Sin embargo, se han desarrollado otros mecanismos de organización, desde reuniónes que recuperan la memoria histórica. Son algunos de ellos:

DC: [...] Es no hacer declarar otra organización, vamos a retomar el poder de las comunidades, (que) tuvieron antes de la guerra y cuando la guerra vino a adueñarse de los poderes de las comunidades, el poder es que si las comunidades planifican, opinan y participan pero el gobierno no toma en cuenta; por eso se acostumbraron que solo viene el orden arriba por eso los alcaldes... es parte de la dominación, el poder lo tienen ellos y ya no nosotros, no podemos opinar si el poder lo tienen ellos y ya no lo respetan, por eso te digo, si vas a tener una asociación eres socio y tienes voz y voto entonces mejor dejemos, porque tanta organización y ino hay una aclaración de la información verdaderai ...En otras comunidades si voy a llegar (me dicen) ¿cómo se llama tu organización?, en vez de preguntar ¿cómo te llamas?, [preguntan] ¿qué proyecto manejan ustedes? Al entender esto -que la escucha no está si no tengo proyecto u organización- tristeza me da cuando digo ino, no soy una asociación! soy parte de las comunidades es que sólo estamos dando las informaciones pero me dicen: ieso si es pérdida de tiempo! ... ahí está el problema grave, la división y el interés...

Ante esto, hay colectividades que hacen críticas sobre las consecuencias que han tenido la entrada de muchas organizaciones no gubernamentales y la gestión de proyectos con requerimientos de financiamiento, sobre todo en las comunidades que tenían una fuerte organización y a quiénes, al término de la guerra, se impusieron agendas especifícas ajenas a las necesidades de 
las comunidades. Por eso, colectividades y agrupaciones plantean reforzar la escucha de la palabra y la dialogicidad.

Otra forma que se ha presentado para reforzar lo común es con la organización de las alcaldías indígenas (OCHOA, 2013), las cuales han sido producto de una larga lucha donde las comunidades han trabajado por mantener su autoridad propia, su estructura política y reconocimiento ya que el Estado y las reformas liberales desintegraron el cuerpo de las autoridades indígenas para imponer composiciones mixtas donde paulatinamente fueron quedando las élites ladinas. Si bien la transformación de las alcaldías no fue igual en todos los espacios, la desaparición de estas figuras y de otras estructuras mermó e invisibilizó las lógicas comunitarias. Además, con las violencias que se desplegaron contra las comunidades en el periodo de la guerra contrainsurgente, se dificultó aún más su reorganización. Si bien la reconformación y luchas por recuperar los espacios políticos como las alcaldías cambian de acuerdo con el departamento y la organización comunal, ha habido un diálogo para compartir las experiencias de ellas y los espacios ganados.

Una de las estrategias que han llevado al cabo es la de tejer formas diversas de lucha desde la organización popular hasta la exigencia del cumplimiento nacional e internacional, de: la Constitución Política de la República de Guatemala - en su Sección 3o. Comunidades Indígenas, ${ }^{9}$ los Convenios de la Municipalidad, los acuerdos emanados del proceso de Paz y el Convenio 169 de la $\mathrm{OIT}^{10}$ en las cuales apelan a la obligación del Estado guatemalteco.

En ese marco, está el Acuerdo sobre Identidad y Derecho de los Pueblos Indígenas, firmado en 1995, el cual versa en uno de sus apartados sobre la defensa de la cultura. Se comprende la cultura como legado de donde provienen las técnicas para "la administración

9 Los artículos 66, 67 y 68 expresan que el Estado guatemalteco reconoce y respeta la diversidad cultural y que las tierras de las comunidades indígenas gozarán de protección especial del Estado. También los artículos 612 y 617 del Código Civil.

10 El inciso 2 del artículo 14 establece que los gobiernos deberán garantizar la protección efectiva de los derechos de propiedad y posesión sobre las tierras de los pueblos indígenas. Guatemala lo ratificó en 1995. 
del territorio, los recursos naturales, inmuebles, muebles, documentos y experiencias transmitidas oralmente, para administrar y gobernar en las comunidades k'iche's" (TZAQUITZAL; IXCHUIÚ; TIÚ, 2000, p. 10). Lo que llevó a la necesidad de reconstruir las autoridades indígenas en el marco fue también el fortalecimiento del movimiento maya (BASTOS; CUMES, 2007), como forma de articular otras resistencias. Aunque estas resistencias no siempre son reconocidas por las municipalidades oficiales, ellas realizan casos de administración de justicia, han visto lo referente a los títulos de las propiedades comunales y han llevado al cabo una lucha amplia por la defensa y toma de decisiones en su territorio.

El trabajo de retomar las alcaldías indígenas, por ejemplo, se ha realizado mediante la escucha y palabra de las y los mayores, como comenta un integrante de Nebaj:

K... Primero los ancianos se platican ¿quién va a tomar el cargo como alcalde municipal?... pensamos que éste. Pero ¿es respetuoso? ¿Tiene la capacidad? Respeta, cumple, no decide solo. Ta bueno, ¿lo animamos, lo decidimos?

Esto implica que uno de los caminos es la unidad comunitaria para la toma de espacios públicos, en donde se presentan diálogos y compromisos entre la comunidad con su respectivo respaldo y el gobierno. Tiene como premisa la validación de la experiencia y conocimiento de las y de los ancianos, así como abrir los espacios de participación de las mujeres, en entrevista Amaité comenta como fue el caso "de la compañera Teresa en la región del Quiché, que llevó a todos a trabajar y propuso que un año gobernara un hombre y otro una mujer cuando no eran pares"

Dentro de la complejidad de los tejidos de las resistencias, se han conformado históricamente sistemas de gobiernos comunales indígenas, en los cuáles - como por ejemplo en Chuimeq'ena' o Totonicapán - el territorio tiene una conformación con cantones que son "la unidad política geográfica que mediante tramas de parentesco estructuran los estamentos territoriales autónomos de organización de gobierno... funcionan actualizando las estructuras patrilineales para delimitarse" (TZUL, 2018, p. 18). Con esta forma de colectividad, se han desarrollado varias rebeliones 
indígenas, donde el sujeto de la política es la comunidad que busca preservar, defender y recuperar los medios de reproducción de la vida en la cual tiene un gran peso el territorio, que difiere de la organización ampliada del movimiento maya, de los mecanismos estatales de reconocimiento de los pueblos indígenas y de otras formas de organización. Algo relevante de este sistema de gobierno comunal es que es la trama comunitaria lo que lo sostiene en tanto es la colectividad que busca defender las tierras comunales y mantener su autogobierno.

Otra trama es el reavivamiento de la memoria/historia que tiene como objetivo alimentar la raíz comunal de vida y organización, ya que en la memoria está el origen, el modo de ser de los pueblos: el origen es el centro del centro, del espacio y del tiempo, plantean algunas comunidades k'ich'e e Ixiles en Guatemala. "Es evidente que mientras haya memoria, habrá origen y mientras haya origen sobrevivirán los pueblos" (MEMORIA HISTÓRICA, 2013, p. 411). Así realizar el tejido de las memorias en tanto territorio ancestral es clave en el ámbito de su defensa y es en ese sentido que se apela no sólo a las formas antiguas de organización y resistencia sino a la forma en que se ha conformado el territorio y las comunidades, como es el caso de los garífunas y afrodescendientes. Compartimos lo que enuncia Tischler Visquerra (2005, p. 15) en tanto "la memoria como conocimiento de la realidad dominante desde la insubordinación", donde se pone en el centro lo común y esta relación se va construyendo con los diferentes lazos que se comparten en las profundidades del estar en la montaña, en la selva, en la costa, en el territorio; es lo común de amanecer, del trabajar, de celebrar algo. Así, lo común de la construcción del tiempo es futuro-pasado:

Nuestra raíz -como todas las raíces- no pueden concebirse sin la tierra. La tierra, que, desde el punto de vista indio, es común. Es en la tierra donde nosotros existimos como seres humanos comunes, es decir, como pueblos, y en ella recreamos nuestra naturaleza y vida mediante el trabajo familiar y colectivo. (REGINO MONTES, [s.f], [s.p.]). 
Lo político adquiere una forma comunal que tiene en el territorio un factor importante de cohesión. Con el desmembramiento y despojo, la reorganización de diferentes formas de resistencia ha sido un proceso paulatino, en el cual se busca que la autodeterminación resida en la colectividad. En este sentido, es relevante ubicar que hay un proceso transversal de lucha y resistencia que está presente en todo momento - la participación de las mujeres, que muchas veces no es relevada o es silenciada y se caracteriza tanto por mantener formas de resistencias comunales, por sostener la comunidad y por formas creativas en el trabajo comunal y sociopolítico.

\section{Tejidos de mujeres}

los planteamientos de las mujeres incorporan diferentes retos y propuestas en la manutención de lo común, desde la lucha por la defensa del territorio en un sentido integal, ya que el primer territorio es el propio cuerpo que se mantiene de la tierra que nos alimenta y nutre. El territorio es el espacio donde se reproduce la vida y se enmarca con todas las relaciones sociales, culturales, espirituales. Por ejemplo, Lorena Cabnal, ${ }^{11}$ mujer maya-xinca defensora del territorio, en diálogo plantea que:

Nosotras estamos luchando por la vida. Nosotras decimos defender el territorio cuerpo es defender el territorio-tierra y defender el territorio tierra es defender también los cuerpos. Estamos en la red de la vida defendiendo el agua, las montañas, eso es vida para la humanidad... (SANANDO...; 2017, [s.p.]).

En este sentido, las luchas y las resistencias de las mujeres van desde las propuestas feministas comunitarias, donde se atiende a una memoria colectiva de saberes para mantener la vida. Para ello, trabajan con los vínculos del universo, las aportaciones de la humanidad, ubicando que, en la base de la red de la vida, como plantea Cabnal, no hay géneros sino movimiento, ${ }^{12}$ por lo que la defensa

\footnotetext{
11 Todas sus palabras que utilizamos en este artículo están tomadas del documental Sanando nuestro territorio-cuerpo-tierra. Cf. Sanando... (2017).

12 En este planteamiento, tenemos claridad que la identidad de género es una reconstrucción bio-socio-cultural-patriarcal, en la cual las mujeres tenemos negados derechos y vivimos la violencia patriarcal.
} 
del territorio implica una comprensión amplia que no es binaria ni antropocéntrica. No sólo se busca parar los proyectos extractivistas sino las violencias existentes y trabajar por otras formas de relacionarse, en donde se de la vincularidad con el universo. También contempla la confianza, reconocimiento y reivindicación de las decisiones, sabiduría e intuición de las mujeres sobre sus cuerpos, lo cual ha sido un trabajo importante tomando en cuenta las derivaciones que tiene para las mujeres alzar la voz en una sociedad patriarcal y ante las violencias epistémicas.

Los trabajos se encaminan a la recuperación de la vida, al equilibrio, a las posibilidades de vivir desde otro paradigma atendiendo que, ante la desintegración múltiple de su corporeidad histórica, desde los tiempos de la invasión, las comunidades han logrado vencer la afrenta de la destrucción de su materialidad humana. ${ }^{13}$

En este sentido, un grupo importante de mujeres ha realizado un profundo trabajo para mantener la salud corpo-espiritual del territorio del cual forman parte. Ellas han alzado la voz en temas específicos y silenciados, desde el ámbito estatal y de las organizaciones políticas, como ha sido nombrar y sanarse ante la violación sistemática a sus cuerpos (CAC, MÉNDEZ, 2015). Ellas han trabajado en la auto comprensión del contexto en el que se han desarrollado, en obtener información sobre diferentes perspectivas de la realidad; se han agrupado para crear colectividades, han reconocido las emociones y tristezas que tienen añejadas en el cuerpo y han realizado la vinculación desde la relación amorosa y de placer, es decir, han cruzado las heridas y se han sanado, lo que presenta puntos importantes para entender por qué se ha posibilitado el tejido de la memoria y la manutención del territorio.

Varias de ellas encabezaron las luchas contra el silencio y la impunidad, de múltiples maneras, con la reconstrucción de la memoria, la lucha por la justicia - poniendo a discusión las formas en que se entiende y se siente la justicia -, la articulación de organización política, que desembocó en un proceso de crítica profunda de la sociedad. Se articularon no sólo al frente de las movilizaciones sociales ante la presencia de la fuerza pública, también

13 Esto lo podemos ubicar en la invasión, en las múltiples formas de opresiones y de dominación vividas. 
mantuvieron los espacios de reproducción de la vida por años, ante la criminalización de los familiares y denunciaron la violencia ejercida por grupos de choque.

Esto lo ejemplifica el relato de Angélica Choc, de la Comunidad Lote Ocho, El Estor, en la cual la comunidad ha luchado contra la Compañía Guatemalteca de Níquel (CGN). Ella dice que:

[...] desde que reiniciaron las operaciones de la CGN, personal de seguridad de la mina ha estado involucrado en el abuso sexual de 11 mujeres, agresiones en contra de comunitarios y destrucción de sus propiedades y medios de vida. Angélica, además, carga con el dolor de que el proyecto minero se cobró la vida de su esposo, Adolfo Ich Chamán, asesinado el 27 de septiembre de 2009 (MUJERES..., [s.f.], [s.p.]).

Choc ha llevado una lucha internacional, en los tribunales, en contra de la minería como responsable de la violación de derechos a su comunidad.

Los espacios con la participación de mujeres y entre mujeres han planteado problemáticas que no se abordaban siempre y han impulsado la cohesión, la solidaridad y propuestas políticas integrales que se centran en el equilibrio comunitario. En esos espacios, también se ponen énfasis en las consecuencias de una sociedad que se ha constituido con formas profundas de dominación y despojo histórico, relevando la fuerza comunitaria de la red de la vida y los límites de un Estado capitalista, racista y colonial.

\section{Reflexiones finales}

Este tejido de resistencias tiene un hilo conductor que podríamos llamar la "vuelta a la semilla", que se refiere principalmente a la posibilidad de las comunidades de retomar su sujetidad política. Entendemos esta sujetidad política como la apropiación y la construcción por las comunidades de las formas de mantener sus relaciones sociales, culturales y espirituales, con autonomía y autodeterminación; también la vemos como la lucha por consolidar una fuerza que permita superar la relación de subalternidad y mantener una vida digna en sus territorios-cuerpos-tierra. La 
sujetidad política comunitaria está pensada en el ámbito territorial como actores que determinan y deciden sobre su territorio, atendiendo a que, en un mismo territorio, se conjugan diversas relaciones políticas que impactan de manera desdoblada en diferentes niveles, en acciones políticas mismas que se conjugan no sólo en el ámbito local, sino en el regional e internacional. Las resistencias han realizado una crítica a la imposición de concepciones temporales y espaciales que mantienen los ejes de dominación, control y arrebatamiento de la fuerza de una población, en los ámbitos simbólicos, concretos y territoriales. Las resistencias no sólo defienden el territorio, sino realizan una crítica profunda a la configuración estatal.

Podemos ubicar como, en las últimas décadas de reconfiguración estatal, con la incorporación de los elementos de un Estado de competencia, los problemas histórico-estructurales siguen en pie y se están gestando transformaciones en la territorialidad de las comunidades y los bienes naturales. El modelo de capitalismo transnacionalizado, dominante y estructurador de las relaciones sociales se profundizó con algunos atenuantes, como el reconocimiento de la ciudadanía, la cual fue un parteaguas en Guatemala. ${ }^{14}$ Sin embargo, debemos recordar que "el ciudadano sólo puede funcionar como tal si se hace total abstracción de todas sus determinaciones sociales concretas" (ACANDA, 2009, p. 94).

La forma en que se planteó la construcción de la ciudadanía evitaba claramente el cuestionamiento a la situación socio política de Guatemala, donde el racismo, la opresión y el dominio seguían asentados, manteniendo el colonialismo interno y el proyecto político opresor de la clase en el poder que, en pos de mantener la acumulación y la ganancia, vendió los bienes del país y abrió la entrada de inversión por medio de los megaproyectos de explotación petrolera, construcción de hidroeléctricas, producción de

14 Por ejemplo, el reconocimiento como "grupos étnicos" por parte del Estado guatemalteco empezó a darse en la constitución de 1985. Sin embargo, el reconocimiento como pueblos indígenas se obtuvo hasta los Acuerdos de Paz sin llegar a ser reconocidos en la constituyente y de manera limitada, pues se centró en derechos culturales, sin incluir los derechos políticos y económicos. Además que el reconocimientono es suficiente, el trabajo es hacer política desde los pueblos. 
agro combustibles, minería e infraestructura. Hoy se produce una ruptura importante con la concepción comunal territorial, porque, desde el Estado, ésta se vincula con la reproducción del capital y con sus necesidades históricas primordiales, dotándola de un sentido que atiende prioritariamente a la acumulación y no a las necesidades de la población. La contradicción entre lo comunitario y el Estado afecta las relaciones con el territorio y ha empujado a múltiples resistencias, que han restituido las formas debilitadas de organización comunitaria todavía frágiles. Éste se ha perdido por el sistema clasificatorio constituido, es decir, la colonialidad del poder (QUIJANO, 2000).

Ha existido un proceso de larga duración, donde la relación del Estado ha mermado la posibilidad de participación y de derechos de las comunidades indígenas y ha mantenido múltiples mediaciones, desde las que van en la conformación de un sentido común que refuerza el racismo estructural y se concibe a la naturaleza hasta el servicio de los seres humanos, el cual niega formas ancestrales de vinculación.

Los procesos de despojo el Estado, poco a poco, dificultaron la participación de las comunidades, como observamos en las políticas liberales que mermaron la participación de las comunidades al tiempo que el Estado configuró en instituciones paralelas a las comunitarias, para romper los tejidos comunes, como es el caso de las alcaldías. En otro ámbito, la oenegeización ha tenido como consecuencia la despolitización y la ruptura de tramas y fortalezas comunitarias, en algunos casos.

En el ámbito comunal, la lucha tampoco ha sido fácil, ya que se han dado rupturas fuertes por diferentes causalidades, entre ellas las contradicciones en el ámbito comunitario, como la existencia de integrantes que han apoyado a las minerías, ${ }^{15}$ la falta de información que también ha hecho con que la defensa territorial lleven otro tiempo diferente al del despojo.

15 Esto se puede ejemplificar en las movilizaciones de trabajadores y proveedores de la minería que, tras el fallola Corte Suprema de Justicia de suspender actividades de la mina, se manifestaron, exigiendo sus derechos laborales. De esto, se presentaron pancartas aludiendo que la minería es desarrollo y el desarrollo es empleo. 
Si bien estos procesos articulan diversas formas de lucha y resistencia, han llevado a reflexionar en como se puede dar el fortalecimiento de las tramas comunitarias, para repensar y sentir las formas de articular las relaciones comunales y resistir ante la complejidad del panorama. Los retos no son sencillos en tanto se necesita que la acción colectiva y comunal logre mantenerse con la diversidad de las necesidades de cada pueblo ante un Estado omiso, corrupto, racista y capturado. En él, se ha dejado claro que el proyecto de nación, en la vía de los hechos, perpetúa los intereses de la clase en el poder, en donde la tierra y el territorio se convierten en un nuevo centro de acumulación auspiciada por los gobiernos que buscan mantener el Estado extractivista que articula también prácticas que incorporaron la explotación, el dominio y la victimización, bajo el discurso de "modernización y progreso", "apegados al Estado de derecho".

Es relevante preguntarse sobre el proyecto político-ideológico de transformación de la realidad, enarbolado por las comunidades, sobre todo considerando la problematización de la construcción de una visión ético-política de comprensión distinta del mundo. También es importante indagar sobre las propuestas de las colectividades de mujeres, que ponen énfasis en la integralidad del proyecto político en tanto lo que se quiere mantener y preservar es la red de la vida, que va mucho más allá de la concepción del Estado-nación, proponiendo otras formas de relación con el universo, las cuales tienen simientes ancestrales. Una de esas propuestas centrales es mantener la semilla, el territorio, el cuerpo-territorio, los modos de los pueblos que tienen que ver con la espiritualidad y la relación entre el "corazón del cielo y el corazón de la tierra", para que, ante la violencia y el despojo, se siembre y germine la vida. 


\section{REFERENCIAS}

ACANDA, J. L. Traducir a Gramsci. La Habana: Editorial Ciencias Sociales, 2009. BASTOS, S.; CUMES, A. (coord.) Mayanización y vida cotidiana: ideologías en tensión, identidad, cultura y modernidad. v. 1. Ciudad de Guatemala: CIRMA, 2007.

BASTOS, S.; CUMES, A. (coord.) Mayanización y vida cotidiana: ideologías en tensión, identidad, cultura y modernidad. v. 1. Ciudad de Guatemala: CIRMA, 2007.

BASTOS, S.; DE LEÓN, Q. Guatemala: construyendo el desarrollo propio en un neoliberalismo de posguerra. Revista pueblos y fronteras digital, San Cristóbal de Las Casas, v. 10, n. 19, p. 52 - 79, 2015. Disponible en: <http://www.scielo.org.mx/scielo.php?script=sci_arttext\&pid=S1870$41152015000100052 \& \operatorname{lng}=$ es\&nrm=iso Acceso en: 7 mar. 2019.

BRAN-GUZMÁN, E. Conflictividad socio ambiental en Centroamérica: una década de rearticulación y movilización social y política. Revista Argumentos, Distrito Federal, México, v. 30, n. 83, p. 43 - 68, 2017.

CABAÑAS, A. Los sueños perseguidos: memoria de las comunidades de Población en Resistencia de la Sierra. Madrid: Gráficas Lizarra, 2000.

CAC - Colectiva Actoras de Cambio; MÉNDEZ, Liduvina. Metodología de formación sanación con mujeres sobrevivientes de violencia sexual y de la guerra en Guatemala. Ciudad de Guatemala: Argrafic, 2015.

COMISIONES Obreras. El plan de operaciones. América Latina en Movimiento, [on line], 27 jul. 2011. Disponible en: <https://www.alainet. org/es/active/48366>. Acceso en: 8 jul. 2019.

LÓPEZ DE LA VEGA, M. Guatemala: Complejidades hegemónicas de las políticas de despojo y coerción entre la resistencia comunitaria. In: Congreso Internacional Los Pueblos Indígenas de América Latina, siglos XIX-XXI: avances, perspectivas y retos, $1^{\circ}$, 2013, Oaxaca. Anales...Oaxaca: Equipo de Comunicación y Análisis Colibrí Zurdo; Prensa Comunitaria, 2013. p. 47 - 63. Disponible en: <http://www. academia.edu/download/48525212/Comunidades_y_Estado_en_Guatemala_Mesa_CIPIAL_Oaxaca_2013.pdf\#page=47> . Acceso en: 8 ene. 2019.

MANÇANO FERNANDES, B. Territorio, teoría y política. In: LOZANO VELÁSQUEZ, F.; FERRO, J. G. G. (eds.). Las configuraciones de los territorios rurales en el siglo XXI. Bogotá: Pontificia universidad Javeriana, 2009. p. $35-66$.

MEMORIA HISTÓRICA. El camino de las palabras de los pueblos. Ciudad de Guatemala: Magna Terra, 2013.

MORENO, E. Desde una larga noche el amanecer apenas empieza. Ciudad de Guatemala: Avancso, 2015.

MUJERES defensoras del abuso de las empresas mineras en Guatemala. Oxfam International, [on line], [s.f.]. Disponible en: <https://www.oxfam. org/es/guatemala/mujeres-defensoras-del-abuso-de-las-empresasmineras-en-guatemala>. Acceso en: 14 abr. 2019. 
NAVARRO, M.; PINEDA, C. Luchas socio ambientales en América Latina y México: en defensa de la tierra, el territorio, los bienes naturales. Berlín: Editorial Académica Española, 2011.

OCHOA, C. F. Trayectoria histórica de las alcaldías indígenas. Momento, Asociación de Investigación $y$ Estudios Sociales, Ciudad de Guatemala, a. 28, n. 4, p. $01-18,2013$.

PANEZ PINTO, A. La lucha por el territorio de los pueblos mayas en Guatemala. Movimiento Mesoamericano contra el modelo extractivo, [on line], 24 jul. 2014, Disponible en: <https://movimientom4. org/2014/07/la-lucha-por-el-territorio-de-los-pueblos-mayas-enguatemala/>. Acceso en: 10 abr. 2019

QUIJANO, A. Colonialidad del poder, eurocentrismo y América Latina. In: LANDER, E. (comp.). La colonialidad del saber, eurocentrismo y ciencias sociales - perspectivas latinoamericanas. Buenos Aires: CLACSO, 2000. p. $201-246$.

REGINO MONTES, A. La comunalidad: raíz, pensamiento, acción y horizontes de los pueblos indígenas. Red Indígena, [on line], [s.f.]. Disponible en: <www.redindigena.net/ser/departamentos/documentos/ comunarealidad.html>. Acceso en: 11 mar. 2017.

ROZITCHNER, L. Efectos psicosociales de la represión en Psicología social de la guerra. El Salvador: UCA Editores, 2000.

SANANDO nuestro territorio-cuerpo-tierra. Entrevista y edición: Laura Chinchilla. Costa Rica: Era Verde; UNED, 2017. 1 vídeo (43 min), son., color. Idioma: Español. Sin subtítulos. Disponible en: <https://www.youtube. com/watch?v=fwba3zTJxvw>. Acceso en: 28 jul. 2019.

SOLANO, L. La Franja Transversal del Norte: Neocolonización en marcha. El Observador, Ciudad de Guatemala, a. 2, n. 7, p. 03 - 27, 2007.

TISCHLER VISQUERRA, S. Guatemala: historia reciente (1954-1996) - Proceso político y antagonismo social. Tomo I. Ciudad de Guatemala: FLACSO, 2012.

TORRES RIVAS, E.; AGUILERA PERALTA, G. Desde el autoritarismo a la Paz. Ciudad de Guatemala: FLACSO, 1998.

TZAQUITZAL, E.; IXCHUIÚ, P.; TIÚ, R. Alcaldes comunales de Totonicapán. Ciudad de Guatemala: Secretaria de Coordinación Ejecutiva de la Presidencia/Unión Europea, 2000.

TZUL, G. Sistemas de gobierno comunal indígena: mujeres y tramas de parentesco en Chuimeq'ena'. Ciudad de México: Sociedad Comunitaria de Estudios Estratégicos. 2018.

VILLATORIO GARCÍA, D. ¿Quién le teme a las consultas comunitarias? Plaza Pública, [on line], 9 oct. 2017. Disponible en: <https://www. plazapublica.com.gt/content/quien-le-teme-las-consultas-comunitarias>. Acceso en: 9 feb. 2019. 